\title{
Полуэмпирическая формула для оценки эффективной длины диффузии фотогенерированных носителей заряда в фотоприемных КРТ-матрицах с квадратными диодами в условиях сканирования линейного пятна засветки диодом при максимальном отборе фототока из абсорбера
}

\author{
В.А. Стучинский, А.В. Вишняков \\ Институт физики полупроводников им. А.В. Ржанова, Новосибирск, \\ 630090, пр. Академика Лаврентьева, 13 \\ тел:+7 (383) 330-4968, факс:+7 (383) 333-2771, эл. почта: stuchin@isp.nsc.ru
}

DOI 10.34077/RCSP2021-158

Знание величин длин диффузии фотогенерированных носителей заряда (ФНЗ) в фотоприемных матрицах на основе материала кадмий-ртуть-теллур (КРТ) в разных режимах работы таких матриц важно как для анализа фотоэлектрических процессов в фотоприемных приборных структурах, так и для понимания того, какие факторы и каким образом определяют значения приборных характеристик соответствующих фотоприемных устройств.

Одним из относящихся сюда вопросов является вопрос о значении эффективной длины диффузии ФНЗ $l_{d}$ eff, реализующейся в матрицах при нормальном режиме их работы со смещенными фотодиодами, действующими как сток для неравновесных носителей заряда. Хотя рассматриваемая длина может быть определена, например, посредством Монте-Карло моделирования процесса диффузии ФНЗ в рассматриваемых структурах, такие расчеты требуют затрат усилий на программирование, а также затрат времени на проведение расчетов. В этих условиях можно было бы приветствовать появление более простых (хотя, может, и приближенных) средств оценки длины $l_{d}$ eff.

В настоящей работе предложена полуэмпирическая формула для оценки упомянутой длины диффузии ФНЗ в фотоприёмных КРТ-матрицах с квадратными диодами и варизоннопассивированными границами слоя абсорбера, реализующейся в условиях сканирования линейного пятна засветки диодом с максимальным отбором фототока из абсорбера диодами матрицы. Интерес здесь представляют прежде всего современные фотоприемные матрицы, в которых объемная длина диффузии в абсорбере $l_{d}$ заметно превосходит размеры как их фоточувствительных элементов, так и фотодиодов. Полуэмпирической выведенная формула названа потому, что при ее получении используются предположения, справедливость которых не являлась очевидной, а устанавливалась сравнением величин искомой длины диффузии, рассчитанных по формуле и полученных в МонтеКарло расчетах диффузии ФНЗ в системе.

Вывод формулы основан на представлении процесса диффузии ФНЗ из линейного пятна засветки как происходящего по трем связанным (обменивающихся ФНЗ) каналам, два из которых имеют поглощающую стенку для ФНЗ, расположенную напротив отражающей стенки. Для каналов такого типа имеется аналитическое выражение для длины диффузии частиц в них [1]. Второй формулой, использованной для вывода формулы для длины $l_{d}$ eff, является закон сложения “парциальных" длин диффузии в каналах в “суммарную” (общую для всех каналов) длину диффузии $l_{d e f f}$, реализующуюся в результате затухания концентрации ФНЗ в каналах и ее выравнивании между каналами на каждом дифференциальном шаге процесса. После принятия некоторых правдоподобных допущений в отношении третьего канала и возникает формула, являющаяся результатом настоящей работы.

Точность полученной формулы была оценена сравнением рассчитанных по ней значений длины диффузии $l_{d}$ eff с величинами $l_{d}$ eff, полученными посредством расчета методом Монте-Карло функции рассеяния линии (англ. - Line Spread Function [2]) для матриц с разными значениями величин конструктивных параметров. В значительной части области актуальных значений параметров типичных матриц (размера диодов и толщины слоя абсорбера под диодами) эта точность оказалась удивительно хорошей, достигающей единиц процентов.

\section{Лuтература}

[1] А.В. Вишняков и др. // J. Appl. Phys. 2015. Vol. 118. P. 124508-(1-9).

[2] L. Martineau et al. // Sensors, Systems, and Next-Generation Satellites XVII, ed. by R. Meynart, S. P. Neeck, and H. Shimoda, Proc. SPIE. Vol. 8889. 88891B. 2013. doi: 10.1117/12.2028883. 